\title{
Article \\ Influence of the FCGR2A rs1801274 and FCGR3A rs396991 Polymorphisms on Response to Abatacept in Patients with Rheumatoid Arthritis
}

\author{
Noelia Márquez Pete ${ }^{1}$, María del Mar Maldonado Montoro ${ }^{2}$, Cristina Pérez Ramírez ${ }^{1,3, *}$, \\ Fernando Martínez Martínez ${ }^{4}$, Juan Enrique Martínez de la Plata ${ }^{5}$, Abdelali Daddaoua ${ }^{6}$ \\ and Alberto Jiménez Morales ${ }^{1}$
}

Citation: Márquez Pete, N.; Maldonado Montoro, M.d.M.; Pérez Ramírez, C.; Martínez Martínez, F.; Martínez de la Plata, J.E.; Daddaoua, A.; Jiménez Morales, A. Influence of the FCGR2A rs1801274 and FCGR3A rs396991 Polymorphisms on Response to Abatacept in Patients with Rheumatoid Arthritis. J. Pers. Med. 2021, 11, 573. https://doi.org/ 10.3390/jpm11060573

Academic Editor: Su-Jun Lee

Received: 29 April 2021

Accepted: 10 June 2021

Published: 18 June 2021

Publisher's Note: MDPI stays neutral with regard to jurisdictional claims in published maps and institutional affiliations.

Copyright: (c) 2021 by the authors. Licensee MDPI, Basel, Switzerland. This article is an open access article distributed under the terms and conditions of the Creative Commons Attribution (CC BY) license (https:// creativecommons.org/licenses/by/ $4.0 /)$.
1 Pharmacy Service, Pharmacogenetics Unit, University Hospital Virgen de las Nieves, 18014 Granada, Spain; noeliamarquezpete@gmail.com (N.M.P.); alberto.jimenez.morales.sspa@juntadeandalucia.es (A.J.M.)

2 Clinical Analysis Service, Hospital Campus de la Salud, 18016 Granada, Spain; mariadelmarmaldonadomontoro@gmail.com

3 Center of Biomedical Research, Department of Biochemistry and Molecular Biology II, Institute of Nutrition and Food Technology “José Mataix”, University of Granada, Avda. del Conocimiento s/n., 18016 Granada, Spain

4 Department of Pharmacy and Pharmaceutical Technology, Social and Legal Assistance Pharmacy Section, Faculty of Pharmacy, University of Granada, 18071 Granada, Spain; femartin@ugr.es

5 Pharmacy Service, Hospital de Poniente-El Ejido, 04700 El Ejido, Spain; juanenriquemartinezdelaplata@gmail.com

6 Department of Biochemistry, Faculty of Pharmacy, University of Granada, 18071 Granada, Spain; daddaoua@ugr.es

* Correspondence: cperezramirez87@ugr.es

Abstract: Abatacept (ABA) is an immunosuppressant indicated for treatment of rheumatoid arthritis (RA). Effectiveness might be influenced by clinical RA variants and single-nucleotide polymorphisms (SNPs) in genes encoding protein FCGR2A (His131Arg) and FCGR3A (Phe158Val) involved in pharmacokinetics of ABA. An observational cohort study was conducted in 120 RA Caucasian patients treated with ABA for 6 and 12 months. Patients with the FCGR2A rs1801274-AA genotype (FCGR2A-p.131His) showed a better EULAR response (OR $=2.43 ; 95 \% \mathrm{CI}=1.01-5.92)$ at 12 months and low disease activity (LDA) at 6 months $(\mathrm{OR}=3.16$; $95 \% \mathrm{CI}=1.19-8.66)$ and 12 months $(\mathrm{OR}=6.62$; $95 \% \mathrm{CI}=1.25-46.89)$ of treatment with ABA. A tendency was observed towards an association between the FCGR3A rs396991-A allele (FCGR3A-p.158Phe) and better therapeutic response to ABA after 12 months of treatment $(p=0.078)$. Moreover, we found a significant association between the lowaffinity FCGR2A/FCGR3A haplotypes variable and LDA after 12 months of ABA treatment (OR = 1.59; $95 \% \mathrm{CI}=1.01-2.58)$. The clinical variables associated with better response to ABA were lower age at starting $\mathrm{ABA}(\mathrm{OR}=1.06 ; 95 \% \mathrm{CI}=1.02-1.11)$ and greater duration of $\mathrm{ABA}$ treatment $(\mathrm{OR}=1.02$; $95 \% \mathrm{CI}=1.01-1.04)$, lower duration of previous biological therapies (OR $=0.99 ; 95 \% \mathrm{CI}=0.98-0.99)$, non-administration of concomitant disease-modifying antirheumatic drugs (DMARDs) $(\mathrm{OR}=24.53$; $95 \% \mathrm{CI}=3.46-523.80)$, non-use of concomitant glucocorticoids (OR $=0.12 ; 95 \% \mathrm{CI}=0.02-0.47)$, monotherapy $(\mathrm{OR}=19.22 ; 95 \% \mathrm{CI}=2.05-343.00)$, lower initial patient's visual analogue scale (PVAS) value $(\mathrm{OR}=0.95 ; 95 \% \mathrm{CI}=0.92-0.97)$, and lower baseline ESR $(\mathrm{OR}=0.92 ; 95 \% \mathrm{CI}=0.87-0.97)$. This study showed that high-affinity FCGR2A-p.131His variant, low-affinity FCGR3A-p.158Phe variant, and combined use of FCGR2A/FCGR3A genetic variations could affect ABA effectiveness. Further studies will be required to confirm these results.

Keywords: rheumatoid arthritis; abatacept; FCGR2A; FCGR3A; effectiveness; polymorphisms

\section{Introduction}

Abatacept (ABA) is an immunosuppressant indicated for treatment of rheumatoid arthritis (RA), psoriatic arthritis, and juvenile idiopathic arthritis ${ }^{1}$. ABA comprises a fusion 
of the extracellular domain of human cytotoxic T-lymphocyte-associated protein 4 (CTLA4) with the fragment crystallizable $(\mathrm{Fc})$ region of human immunoglobulin $\mathrm{G} 1$ (IgG1) [1]. The mechanism of action of ABA is based on interaction of CTLA4 with the CD80/CD86 complex, preventing the latter from binding with the CD28 membrane receptor of T lymphocytes [2]. Consequently, the co-stimulatory signal for $\mathrm{T}$ cell activation is blocked [2]. The function of the Fc region of IgG is to improve the pharmacokinetics of ABA, increasing its stability and prolonging the half-life of the drug [3,4]. In addition, the Fc region of IgG1 binds to the Fc-gamma receptors (FCGRs) given rise to a series of immune reactions such as apoptosis, cytokine release, antibody-dependent cellular cytotoxicity (ADCC), and macrophage-mediated immune complex elimination [5-8]. For this reason, the FCGRs play a part in innate and acquired immune activation and have been extensively investigated for their role in the pharmacogenetic of biological therapies (BTs) [4,9-12]. Several subtypes of FCGRs have been described, the most extensively studied being FCGR2A and FCGR3A [13,14]. The protein FCGR2A is expressed on monocytes, macrophages, dendritic cells, neutrophils, and platelets, inducing immune reactions such as phagocytosis of opsonized IgGs, ADCC, reactive oxygen species production, and cytokine production [15]. Similarly, FCGR3A is expressed on monocytes, macrophages, neutrophils, and NK cells, promoting phagocytosis and ADCC mechanisms [15]. The affinity of FCGR2A and FCGR3A for the Fc region of IgG of ABA could vary due to structural changes in extracellular domain of the receptors, which could interfere with the therapeutic response to ABA $[13,14]$. The FCGR structural changes could be produced by single-nucleotide polymorphisms (SNPs) located in the genetic coding region of FCGR2A and FCGR3A $[13,14]$. The FCGR2A rs1801274 (A > G) polymorphism gives rise to a histidine (His) to arginine (Arg) substitution (His131Arg) [16,17]. As has been observed in previous studies, the FCGR2A with His instead of Arg at position 131 showed greater affinity for IgG1 [18]. The rs396991 (A > C) polymorphism located on the FCGR3A gene produces a phenylalanine (Phe) to valine (Val) substitution (Phe158Val) [19]. The Val158 variant showed a greater affinity for IgG1, IgG2, and IgG3, which was associated with greater immune response (ADCC, apoptosis) [19,20]. Studies conducted on tumor necrosis factor inhibitors (TNFis) have evaluated the relationship of these SNPs to the effectiveness and variation in clearance of the drug, obtaining contradictory results $[4,9,11,21-25]$. The low affinity variants FCGR2A-p.131Arg and FCGR3A-p.158Phe could decrease the binding of ABA to the receptors, and thus its clearance would be lower, increasing the therapeutic effect [18]. Cañete et al. showed that patients undergoing treatment with infliximab (IFX) and carrying the FCGR2A rs1801274-GG and FCGR3A rs396991-AA genotypes, both low-affinity, exhibited lower clearance of the drug, and that its therapeutic effect, and consequently the response to therapy, therefore increased [18]. Similarly, these SNPs are related to the development of autoimmune diseases [26]. Low-affinity receptors could present less binding and clearance of autoimmune complexes, increasing tissue damage in patients carrying low-affinity variants and producing less response to treatment [15]. Another recent study, performed by Jiménez Morales et al., identified the high-affinity genotype FCGR2A rs1801274-TT and allele FCGR3A rs396991-G as predictors of greater therapeutic response to rituximab (RTX) and the low-affinity genotype FCGR3A rs396991-TT as a predictor of good response to tocilizumab (TCZ) [9]. Theories about the influence of FCGR2A and FCGR3A SNPs in response to BTs are multiple and the effect of the interaction of these receptors with biologic drugs is unknown. Nevertheless, these SNPs could determine the great interindividual variability in the response to $\mathrm{ABA}$; the therapeutic failure rate is approximately $30 \%$ [27]. However, no previous study has evaluated the relationship between the FCGR2A rs1801274 and FCGR3A rs396991 SNPs and ABA response in patients diagnosed with RA. Recently, SNPs have been investigated in genes related to the mechanism of action of ABA, such as CTLA-4 (rs5742909, rs231775), which could be associated with ABA response [28].

Within this conceptual framework, the objective of this study was to evaluate the involvement of the FCGR2A rs1801274 and FCGR3A rs396991 SNPs and low-affinity FCGR2A/FCGR3A haplotypes as possible biomarkers of response to ABA (EULAR re- 
sponse, low disease activity (LDA), and remission) after 6 and 12 months of treatment in patients diagnosed with RA.

\section{Materials and Methods}

\subsection{Study Design}

We conducted a retrospective observational cohort study.

\subsection{Ethics Statements}

The study was carried out with the approval of the Ethics and Research Committee of the University Hospital Virgen de las Nieves (HUVN) in accordance with the Declaration of Helsinki. The subjects who participated in the study signed an informed consent for collection and genetic analysis of saliva samples and for their donation to the Andalusian Public Health System Biobank. The samples were identified by alphanumeric codes.

\subsection{Study Population}

The study was conducted at the HUVN in Granada, Spain. We recruited 120 patients over the age of 18 years diagnosed with RA in the Rheumatology Department of the HUVN, according to the American College of Rheumatology (ACR) classification criteria [29], treated with $\mathrm{ABA}$ for a period of at least 6 months. ABA was administered intravenously (IV), in doses of $500 \mathrm{mg}(<60 \mathrm{~kg}), 750 \mathrm{mg}(60-100 \mathrm{~kg})$, or $1.000 \mathrm{mg}(>100 \mathrm{~kg})$, in weeks 0, 2, and 4 , respectively, and every 4 weeks subsequently at the same doses in 52 patients, or subcutaneously (SC) at $125 \mathrm{mg}$ /week in 68 patients.

\subsection{Sociodemographic and Clinical Variables}

The sociodemographic and clinical data were collected by reviewing clinical histories. The sociodemographic data collected were sex, smoking, age at RA diagnosis, number of years with disease, age at start and duration of ABA treatment, mode of administration of the drug (IV or SC), concomitant GCs, concomitant csDMARDs (methotrexate (MTX), leflunomide (LFN)), number and duration of previous BTs, and reason for suspension of ABA. In addition, the clinical data collected were Disease Activity Score in 28 joints (DAS28) [30-32], Health Assessment Questionnaire (HAQ) score, C-reactive protein (CRP) level, erythrocyte sedimentation rate (ESR), presence of rheumatoid factor (RF), anticitrullinated protein antibodies (ACPA), number of painful joints (NPJ), number of swollen joints (NSJ), and patient visual analogue scale (PVAS).

\subsection{Genetic Variables}

\subsubsection{DNA Isolation}

Following the patients' inclusion and signing of the informed consent, saliva samples were collected with buccal swabs (OCR-100). The DNA was extracted using the QlAamp DNA Mini Kit (Qiagen GmbH, Hilden, Germany), following the manufacturer's instructions for purifying DNA from saliva, and stored at $-40{ }^{\circ} \mathrm{C}$. The DNA concentration and purity were measured using a NanoDrop $2000 \mathrm{UV}$ spectrophotometer with the absorbance ratio at $280 / 260$ and $280 / 230$.

\subsubsection{Detection of Gene Polymorphisms}

The FCGR2A rs1801274 and FCGR3A rs396991 gene polymorphisms were analyzed by real-time polymerase chain reaction (PCR) using TaqMan ${ }^{\circledR}$ probes (ABI Applied Biosystems, Waltham, MA, USA, 7300 Real-Time PCR System). The assay IDs used were FCGR2A (rs1801274) C__9077561_20 and FCGR3A (rs396991) C_25815666_10. The genetic variables were determined with StepOne v2.3 software.

\subsection{Response Variables}

The clinical response was evaluated after 6 and 12 months of ABA treatment and was categorized as EULAR response, LDA, or remission. The EULAR response was evaluated 
according to the European League Against Rheumatism criteria [33] and was classified as satisfactory (DAS28 $<3.2$ ) or unsatisfactory (DAS28 $\geq 3.2$ ) [29,34]. Low disease activity was established for values in the range $2.6 \leq$ DAS28 $\leq 3.2[29,32]$ and remission for DAS28 $<2.6[29,33,35]$.

\subsection{Statistical Analysis}

The descriptive analysis was performed using R 3.5.1 software. The quantitative variables were expressed as the mean ( \pm standard deviation) for those that complied with normality and as the median and percentiles (25 and 75) for the variables that did not follow a normal distribution. Normality was confirmed by the Shapiro-Wilk test. The bivariate analysis between the response and the genetic variables was performed using Pearson's chi-squared test or applying Fisher's exact test for the qualitative variables. For the quantitative variables, Student's $t$-test was applied to the variables that complied with normality. The Mann-Whitney $U$ test was applied for non-normal variables. The lowaffinity FCGR2A/FCGR3A haplotype variable was analyzed as a quantitative variable. The alleles considered as low-affinity for the polymorphisms studied were FCGR2A rs1801274G (FCGR2A-p.131Arg) and FCGR3A rs396991-A (FCGR3A-p.158Phe), whereas FCGR2A rs1801274-A (FCGR2A-p.131His) and FCGR3A rs396991-C (FCGR3A-p.158Val) are highaffinity alleles [18-20]. Transformation from a categorical to a quantitative variable was performed by assigning a score to each allele. A value of 0 was assigned to each of the FCGR2A rs1801274-A and FCGR3A rs396991-C alleles, being high-affinity alleles, while the value 1 was assigned to the low-affinity alleles FCGR2A rs1801274-G and FCGR3A rs396991A. As each patient had four alleles, two for each polymorphism, the score assigned was from 0 to 4 , where 0 signified the absence of low-affinity alleles (AACC) and 4 signified the presence of four low-affinity alleles (GGAA).

Multivariate analysis (logistic or linear regression) was used to calculate the adjusted odds ratio (OR) and $95 \%$ confidence interval $(95 \% \mathrm{CI})$ for potential prognostic factors for EULAR response, LDA, and remission. The goodness of fit for each model was analyzed with the Hosmer-Lemeshow test and the omnibus test of coefficients, and the Cox-Snell and Nagelkerke $r^{2}$ coefficients were also calculated. All tests were two-sided, with a probability of 0.05 or less being considered statistically significant, and were performed using $\mathrm{R}$ 3.5.1 or PLINK toolset free-access software for whole-genome association analysis [36-38].

We determined the Hardy-Weinberg equilibrium and the haplotype frequencies and calculated Lewontin's D-prime $\left(\mathrm{D}^{\prime}\right)$ and the linkage disequilibrium coefficient $\left(r^{2}\right)$. The linkage disequilibrium (LD) for each polymorphism was calculated with the PLINK genome association analysis program [37]. The haplotype frequencies and their association with the response variable were analyzed using the snpStats program, a web-based tool for analysis of association studies [39-43].

\section{Results}

\subsection{Patient Characteristics}

A total of 120 patients receiving ABA as treatment were included in the study. The clinical and sociodemographic data are shown in Table 1. Of all the patients diagnosed with RA, the mean age at diagnosis was $45.15 \pm 13.72$ years; $74.17 \%(89 / 120)$ were women. All the patients were treated with other DMARDs for a median period of 36 (24-72) months. The median number of previous BTs was 2 (1-3). The percentage of ABA-naïve patients was $12.50 \%(15 / 120)$. The mean age at starting ABA was $56.63 \pm 13.03$ years, and the median duration of treatment with ABA was 24 (14.75-44.25) months. In our cohort, 5.83\% (7/120) received ABA treatment as monotherapy during the study period. Concomitant MTX and GC were received by $35 \%(42 / 120)$ and $85 \%(102 / 120)$, respectively. The mean DAS28 score on starting ABA was $4.70 \pm 1.43$. The description of the clinical and sociodemographic parameters is shown in Table 1. 
Table 1. Clinical and demographic features of RA patients treated with abatacept.

\begin{tabular}{|c|c|c|c|}
\hline \multirow[t]{2}{*}{ Variables } & \multicolumn{3}{|c|}{ Initial Level } \\
\hline & $\mathbf{N}$ & $(\%)$ & Mean $\pm S D / p_{50}\left(p_{25}-p_{75}\right)$ \\
\hline Sex & 120 & & \\
\hline Women & 89 & 74 & - \\
\hline \multicolumn{4}{|l|}{ Smoking } \\
\hline Smoker & 18 & 15 & - \\
\hline Ex-smoker & 14 & 12 & - \\
\hline Non-smoker & 88 & 73 & - \\
\hline Age at Dx & 120 & - & $45.15 \pm 13.72$ \\
\hline Years with RA & 120 & - & $24(9-21)$ \\
\hline ABA start age & 120 & - & $56.63 \pm 13.03$ \\
\hline ABA duration & 120 & - & $24.00(14.75-44.25)$ \\
\hline \multicolumn{4}{|l|}{ Administration } \\
\hline $\mathrm{SC}$ & 68 & 57 & - \\
\hline \multicolumn{4}{|l|}{ Concomitant csDMARDs } \\
\hline MTX & 42 & 35 & - \\
\hline LFN & 14 & 12 & - \\
\hline none & 64 & 53 & - \\
\hline \multicolumn{4}{|l|}{ Concomitant GCs } \\
\hline Yes & 102 & 85 & - \\
\hline \multicolumn{4}{|l|}{ Monotherapy } \\
\hline No & 113 & 94 & - \\
\hline Number previous BTs & 120 & - & $2(1-3)$ \\
\hline Duration previous BTs & 120 & - & $36(24-72)$ \\
\hline \multicolumn{4}{|l|}{ Previous BTs } \\
\hline Naïve & 15 & 12 & - \\
\hline $1 \mathrm{TNF}$ & 31 & 26 & - \\
\hline 2 TNFs & 34 & 28 & - \\
\hline 3 or more TNFs & 40 & 33 & - \\
\hline \multicolumn{4}{|l|}{ Reason for suspension } \\
\hline Primary failure & 25 & 21 & - \\
\hline Secondary failure & 12 & 10 & - \\
\hline $\mathrm{AR}$ & 6 & 5 & - \\
\hline $\begin{array}{c}\text { No suspension } \\
\text { RF }\end{array}$ & 77 & 64 & - \\
\hline $\begin{array}{c}\text { Positive } \\
\text { ACPA }\end{array}$ & 96 & 80 & - \\
\hline Positive & 85 & 71 & - \\
\hline DAS28 & 120 & - & $4.70 \pm 1.43$ \\
\hline Baseline NPJ & 120 & - & $6(3-10)$ \\
\hline Baseline NSJ & 120 & - & $3(0-6)$ \\
\hline PVAS & 120 & - & $70(50-80)$ \\
\hline Baseline CRP & 120 & - & $2(1-4)$ \\
\hline Baseline ESR & 120 & - & $22(10-38)$ \\
\hline HAQ & 120 & - & $1.75(1.00-2.00)$ \\
\hline
\end{tabular}

ABA: abatacept; ACPA: anti-citrullinated protein antibody; AR: adverse reaction; BT: biological therapy; CRP: C-reactive protein; csDMARD: conventional synthetic disease-modifying antirheumatic drug; DAS28: disease activity score in 28 joints; Dx: diagnosis; ESR: erythrocyte sedimentation rate; GC: glucocorticoid; HAQ: Health Assessment Questionnaire; IV: intravenous; LFN: leflunomide; MTX: methotrexate; NPJ: number of painful joints: NSJ: number of swollen joints; p: percentile; PVAS: patient visual analogue scale; RA: rheumatoid arthritis; RF: rheumatoid factor; SC: subcutaneous; SD: standard deviation; TNFi: tumor necrosis factor inhibitor.

\subsection{Clinical Effectiveness of $A B A$}

The effectiveness of ABA was evaluated in 120 (93.75\%) and 105 (82.03\%) patients after 6 and 12 months of treatment, respectively (Table 2). After 6 months of ABA therapy, $31.67 \%(38 / 120)$ of individuals showed satisfactory EULAR response, $20 \%(24 / 120)$ had LDA, and 15\% (18/120) had entered the remission phase of the disease. Furthermore, after 12 months of therapy with ABA, 45.71\% (48/105) of subjects showed satisfactory EULAR response, $22.86 \%(24 / 105)$ exhibited LDA, and 27.62\% (29/105) had remission of RA. In 
ABA-bionaïve patients, EULAR response was satisfactory in 53.33\% (8/15) of cases after 6 months of treatment and increased to $78.57 \%(11 / 14)$ after 12 months of treatment. The percentage with LDA was 33.33\% (5/15) after 6 months of treatment and $21.43 \%(3 / 14)$ after 12 months of treatment with ABA, while $20 \%(3 / 15)$ of patients attained remission after 6 months of ABA treatment, rising to 64.29\% (9/14) after 12 months with ABA. All these results are set out in detail in Table 2.

Table 2. Clinical Effectiveness of Abatacept in no-bionaïve and ABA-bionaïve patients.

\begin{tabular}{|c|c|c|c|c|}
\hline \multicolumn{5}{|c|}{ No-Bionaïve Patients } \\
\hline \multirow[t]{2}{*}{ Response Variable } & \multicolumn{2}{|c|}{6 Months } & \multicolumn{2}{|c|}{12 Months } \\
\hline & $\mathbf{N}$ & $\%$ & $\mathbf{N}$ & $\%$ \\
\hline EULAR response & 120 & & 105 & \\
\hline Satisfactory & 38 & 31.67 & 48 & 45.71 \\
\hline Unsatisfactory & 82 & 68.33 & 57 & 54.29 \\
\hline Remission (DAS28 < 2.6) & 18 & 15 & 29 & 27.62 \\
\hline LDA $(2.6 \leq$ DAS28 $\leq 3.2)$ & 24 & 20 & 24 & 22.86 \\
\hline \multicolumn{5}{|c|}{ ABA-bionaïve patients } \\
\hline Response variable & \multicolumn{2}{|c|}{6 months } & \multicolumn{2}{|c|}{12 months } \\
\hline EULAR response & 15 & & 14 & \\
\hline Satisfactory & 8 & 53.33 & 11 & 78.57 \\
\hline Unsatisfactory & 7 & 46.67 & 3 & 21.43 \\
\hline Remission (DAS28 < 2.6) & 3 & 20 & 9 & 64.29 \\
\hline LDA $(2.6 \leq \mathrm{DAS} 28 \leq 3.2)$ & 5 & 33.33 & 3 & 21.43 \\
\hline
\end{tabular}

DAS28: disease activity score in 28 joints; EULAR: European League Against Rheumatism criteria; LDA: lowactivity disease; TNFi: tumor necrosis factor inhibitor.

\subsection{Distribution of the Genotypes Analyzed}

All the gene polymorphism distributions were in agreement with those expected according to the Hardy-Weinberg equilibrium (HWE) model (Table S1). The $\mathrm{D}^{\prime}$ linkage disequilibrium (LD) and $r^{2}$ values are given in Table S2. All the polymorphisms showed minor allele frequencies higher than $1 \%$, and none of them were excluded from the analysis (Table S3).

\subsection{ABA Response Predictors at 6 Months}

\subsubsection{EULAR Response}

After the bivariate analysis, greater EULAR response was found in patients with lower disease duration $(\mathrm{OR}=0.94 ; 95 \% \mathrm{CI}=0.89-0.99)$, without concomitant $\mathrm{GCs}(\mathrm{OR}=4.30 ; 95 \%$ $\mathrm{CI}=1.36-14.55)$, in monotherapy $(\mathrm{OR}=14.82 ; 95 \% \mathrm{CI}=1.69-704.16)$, and with lower duration of treatment with previous BTs $(\mathrm{OR}=0.98 ; 95 \% \mathrm{CI}=0.97-0.99)$ (Table S10). The clinical variables that showed an association with satisfactory EULAR response were lower baseline levels of DAS28 (OR $=0.42 ; 95 \% \mathrm{CI}=0.90-1.89)$, NPJ $(\mathrm{OR}=0.84 ; 95 \% \mathrm{CI}=0.75-0.92)$, NSJ $(\mathrm{OR}=0.79 ; 95 \% \mathrm{CI}=0.67-0.91)$, PVAS (OR $=0.94 ; 95 \% \mathrm{CI}=0.92-0.97)$, $\mathrm{ESR}(\mathrm{OR}=0.97$; $95 \% \mathrm{CI}=0.94-0.99)$, and HAQ (OR $=0.32 ; 95 \% \mathrm{CI}=0.16-0.58)$ (Table S10).

With regard to the pharmacogenetic variables, a tendency was found in our patients towards association between the FCGR2A rs1801274-AA genotype and satisfactory EULAR response (AA vs. G; $p=0.056$; Table S10). The multivariate analysis showed that the independent variables associated with satisfactory EULAR response after 6 months of treatment were lower duration of previous BTs $(\mathrm{OR}=0.98 ; 95 \% \mathrm{CI}=0.97-0.99)$, nonadministration of concomitant DMARDs (OR $=24.53 ; 95 \% \mathrm{CI}=3.46-523.80)$, and the FCGR2A rs1801274-AA genotype (AA vs. G; OR $=2.43 ; 95 \% \mathrm{CI}=1.01-5.92$ ) (Table 3). 
Table 3. Predictors of response at 6 and 12 months of treatment with abatacept in rheumatoid arthritis patients (multivariate analysis).

\begin{tabular}{|c|c|c|c|c|c|c|c|}
\hline $\begin{array}{c}\text { Response } \\
\text { Variable }\end{array}$ & $\begin{array}{c}\text { Independent } \\
\text { Variable }\end{array}$ & B & OR & $\begin{array}{c}p \text {-Value } \\
\text { (Variable) }\end{array}$ & $95 \% \mathrm{CI}$ & $R^{2}$ & Goodness of Fit \\
\hline \multicolumn{8}{|c|}{6 MONTHS } \\
\hline \multicolumn{8}{|c|}{ EULAR response } \\
\hline & $\begin{array}{c}\text { Duration previous } \\
\text { BTs }\end{array}$ & -0.017 & 0.98 & 0.006 & $0.97-0.99$ & \multirow{2}{*}{ Cox Snell $R^{2}=0.173$} & \multirow[t]{2}{*}{$\chi^{2}=9.750$} \\
\hline & $\begin{array}{c}\text { FCGR2A (AA vs. } \\
\text { G) }\end{array}$ & 0.887 & 2.43 & 0.048 & $1.01-5.92$ & & \\
\hline & $\begin{array}{c}\text { Monotherapy (yes } \\
\text { vs. no) }\end{array}$ & 3.199 & 24.53 & 0.006 & $3.46-523.80$ & Nagelkerke $R^{2}=0.243$ & $p=0.283$ \\
\hline \multicolumn{8}{|c|}{ LDA } \\
\hline \multirow{2}{*}{\multicolumn{2}{|c|}{$\begin{array}{c}\text { Initial PVAS } \\
\text { FCGR2A (AA vs. } \\
\text { G) }\end{array}$}} & -0.033 & 0.97 & 0.003 & $0.95-0.99$ & Cox Snell $R^{2}=0.110$ & $\chi^{2}=9.606$ \\
\hline & & 1.149 & 3.16 & 0.022 & $1.19-8.66$ & Nagelkerke $R^{2}=0.174$ & $p=0.294$ \\
\hline \multicolumn{8}{|c|}{ Remission } \\
\hline \multirow{4}{*}{\multicolumn{2}{|c|}{$\begin{array}{c}\text { ABA duration } \\
\text { Duration previous } \\
\text { BTs } \\
\text { Initial ESR } \\
\text { Monotherapy (yes } \\
\text { vs. no) }\end{array}$}} & 0.023 & 1.02 & 0.026 & $1.01-1.04$ & \multirow{2}{*}{ Cox Snell $R^{2}=0.232$} & \multirow{2}{*}{$\chi^{2}=3.338$} \\
\hline & & -0.023 & 0.98 & 0.029 & $0.95-0.99$ & & \\
\hline & & -0.079 & 0.92 & 0.005 & $0.87-0.97$ & \multirow{2}{*}{ Nagelkerke $R^{2}=0.406$} & \multirow{2}{*}{$p=0.911$} \\
\hline & & 2.956 & 19.22 & 0.019 & $2.05-343.00$ & & \\
\hline \multicolumn{8}{|c|}{12 MONTHS } \\
\hline \multicolumn{8}{|c|}{ EULAR response } \\
\hline \multirow{2}{*}{\multicolumn{2}{|c|}{$\begin{array}{c}\text { Initial PVAS } \\
\text { Duration previous } \\
\text { BTs }\end{array}$}} & -0.056 & 0.95 & $<0.001$ & $0.92-0.97$ & Cox Snell $R^{2}=0.248$ & $\chi^{2}=13.130$ \\
\hline & & -0.012 & 0.99 & 0.029 & $0.98-0.99$ & Nagelkerke $R^{2}=0.332$ & $p=0.108$ \\
\hline \multicolumn{8}{|c|}{ LDA } \\
\hline & $\begin{array}{c}\text { ABA start age } \\
\text { Concomitant GCs }\end{array}$ & $\begin{array}{c}0.059 \\
-2.149\end{array}$ & $\begin{array}{l}1.06 \\
0.12\end{array}$ & $\begin{array}{l}0.007 \\
0.004\end{array}$ & $\begin{array}{l}1.02-1.11 \\
0.02-0.47\end{array}$ & Cox Snell $R^{2}=0.196$ & $\chi^{2}=15.030$ \\
\hline & $\begin{array}{c}\text { FCGR2A (AA vs. } \\
\text { AG) }\end{array}$ & 2.551 & 12.82 & 0.002 & $2.95-83.04$ & \multirow{2}{*}{ Nagelkerke $R^{2}=0.297$} & \multirow[t]{2}{*}{$p=0.059$} \\
\hline & $\begin{array}{c}\text { FCGR2A (AA vs. } \\
\text { GG) }\end{array}$ & 1.890 & 6.62 & 0.036 & $1.25-46.89$ & & \\
\hline \multicolumn{8}{|c|}{ Remission } \\
\hline & $\begin{array}{c}\text { Duration previous } \\
\text { BTs }\end{array}$ & -0.019 & 0.98 & 0.006 & $0.97-0.99$ & Cox Snell $R^{2}=0.190$ & $\chi^{2}=7.215$ \\
\hline & Initial PVAS & -0.042 & 0.96 & $<0.001$ & $0.94-0.98$ & Nagelkerke $R^{2}=0.274$ & $p=0.514$ \\
\hline
\end{tabular}

ABA: abatacept; BT: biological therapy; CI: confidence interval; ESR: erythrocyte sedimentation rate; EULAR: European League Against Rheumatism criteria; GC: glucocorticoid; LDA: low disease activity; OR: odds ratio; PVAS: patient visual analogue scale.

\subsubsection{Low Disease Activity (LDA)}

In the bivariate analysis, it was found that lower values of the DAS28 (OR $=0.67 ; 95 \%$ $\mathrm{CI}=0.47-0.93)$, initial PVAS (OR $=0.96 ; 95 \% \mathrm{CI}=0.94-0.98)$, and initial HAQ (OR $=0.49$; $95 \%$ CI $=0.25-0.94$ ) clinical variables were associated with LDA (Table S11). The FCGR2A rs1801274-AA genotype was found to be associated with LDA (AA vs. G; OR $=2.67 ; 95 \%$ $\mathrm{CI}=0.96-7.44)$. In the multivariate analysis, LDA was found to be associated with a lower initial PVAS value (OR $=0.97 ; 95 \% \mathrm{CI}=0.95-0.99)$ and the $F C G R 2 A$ rs1801274-AA genotype (AA vs. G; $\mathrm{OR}=3.16 ; 95 \% \mathrm{CI}=1.19-8.66$ ) (Table 3 ).

\subsubsection{Remission}

Remission of the disease after 6 months of ABA treatment was associated, in the bivariate analysis, with patients who had been receiving $A B A$ therapy for longer $(\mathrm{OR}=1.02$; $95 \% \mathrm{CI}=1.01-1.03)$, without concomitant GCs $(\mathrm{OR}=5.16$; $95 \% \mathrm{CI}=1.40-18.58)$, with $\mathrm{ABA}$ in monotherapy ( $\mathrm{OR}=9.13 ; 95 \% \mathrm{CI}=1.39-68.97)$ and with lower duration of previous BTs $(\mathrm{OR}=0.98 ; 95 \% \mathrm{CI}=0.96-0.99)$ (Table S12). As for the clinical variables, remission was associated with lower values for initial DAS28 ( $\mathrm{OR}=0.44 ; 95 \% \mathrm{CI}=0.27-0.66)$, baseline NPJ $(\mathrm{OR}=0.79 ; 95 \% \mathrm{CI}=0.66-0.91)$, baseline NSJ $(\mathrm{OR}=0.68 ; 95 \% \mathrm{CI}=0.49-0.86)$, initial PVAS $(\mathrm{OR}=0.95 ; 95 \% \mathrm{CI}=0.92-0.97)$, baseline ESR $(\mathrm{OR}=0.94 ; 95 \% \mathrm{CI}=0.89-0.98)$, and initial HAQ (OR $=0.32 ; 95 \% \mathrm{CI}=0.14-0.67)$ (Table S12). The multivariate analysis showed that the independent variables associated with remission of the disease were greater duration of ABA therapy $(\mathrm{OR}=1.02 ; 95 \% \mathrm{CI}=1.01-1.04)$, lower duration of previous $\mathrm{BTs}(\mathrm{OR}=0.98$; 
95\% CI $=0.95-0.99)$, lower baseline ESR (OR $=0.92 ; 95 \% \mathrm{CI}=0.87-0.97)$, and monotherapy $(\mathrm{OR}=19.22 ; 95 \% \mathrm{CI}=2.05-343.00)$ (Table 3$)$.

\subsection{ABA Response Predictors at 12 Months}

\subsubsection{EULAR Response}

In the bivariate analysis, a greater EULAR response was found in patients without concomitant GCs $(\mathrm{OR}=4.42 ; 95 \% \mathrm{CI}=1.32-14.78)$ who were treated in monotherapy $(\mathrm{OR}=7.86 ; 95 \% \mathrm{CI}=0.93-68.99)$ and were ABA-bionaïve $(\mathrm{OR}=0.17 ; 95 \% \mathrm{CI}=0.03-0.71)$ (Table S10). As regards the clinical variables, a satisfactory EULAR response was found to be associated with lower values for initial DAS28 $(\mathrm{OR}=0.68 ; 95 \% \mathrm{CI}=0.49-0.91)$, baseline NPJ (OR $=0.94 ; 95 \% \mathrm{CI}=0.87-1.01)$, initial PVAS (OR $=0.95 ; 95 \% \mathrm{CI}=0.93-0.97)$, and initial HAQ $(\mathrm{OR}=0.39 ; 95 \% \mathrm{CI}=0.21-0.71)$ (Table S10). With respect to the pharmacogenetic variables, a tendency was found towards an association between the FCGR3A rs396991-A allele and satisfactory EULAR response (A vs. CC; $p=0.078$ ) (Table S10). After the multivariate analysis, the independent variables associated with satisfactory EULAR response were a lower initial PVAS value $(\mathrm{OR}=0.95 ; 95 \% \mathrm{CI}=0.92-0.97)$ and lower duration of previous $\mathrm{BTs}(\mathrm{OR}=0.99 ; 95 \% \mathrm{CI}=0.98-0.99)$ (Table 3$)$.

\subsubsection{Low Disease Activity (LDA)}

In the bivariate analysis, low disease activity was associated with individuals who started ABA therapy at an older age $(\mathrm{OR}=1.04 ; 95 \% \mathrm{CI}=1.00-1.09)$ and who received it without concomitant $\mathrm{GCs}(\mathrm{OR}=3.29 ; 95 \% \mathrm{CI}=1.07-10.10)$ and in monotherapy $(\mathrm{OR}=5.2$; $95 \% \mathrm{CI}=1.08-25.30$ ) (Table S11). An association was found between the FCGR2A rs1801274G genotype and LDA ( $\mathrm{G}$ vs. AA; OR $=4.57 ; 95 \% \mathrm{CI}=1.26-16.59$ ) (Table S11). The multivariate analysis showed an association between LDA and older age on starting $\mathrm{ABA}(\mathrm{OR}=1.06$; $95 \% \mathrm{CI}=1.02-1.11)$, non-use of concomitant GCs (OR $=0.12 ; 95 \% \mathrm{CI}=0.02-0.47)$, and the FCGR2A rs1801274-AG genotype (AG vs. AA/GG; OR $=12.82 ; 95 \% \mathrm{CI}=2.95-83.04$ ) (Table 3).

\subsubsection{Remission}

In the bivariate analysis, the variables associated with remission were lower number $(\mathrm{OR}=0.64,95 \% \mathrm{CI}=0.42-0.94)$ and lower duration $(\mathrm{OR}=0.98 ; 95 \% \mathrm{CI}=0.97-0.99)$ of previous BTs (Table S12). Moreover, ABA-bionaïve patients showed greater remission $(\mathrm{OR}=6.60 ; 95 \% \mathrm{CI}=1.67-29.62)$ (Table S12). The clinical variables associated with remission were lower values for baseline NPJ (OR $=0.91 ; 95 \% \mathrm{CI}=0.82-1.00)$, initial PVAS $(\mathrm{OR}=0.97 ; 95 \% \mathrm{CI}=0.95-0.99)$, and initial HAQ $(\mathrm{OR}=0.43 ; 95 \% \mathrm{CI}=0.22-0.80)$ (Table S12). In the multivariate analysis, the independent variables associated with remission of the disease were lower duration of previous BTs $(\mathrm{OR}=0.98 ; 95 \% \mathrm{CI}=0.97-0.99)$ and a lower initial PVAS value (OR $=0.96 ; 95 \% \mathrm{CI}=0.94-0.98)$ (Table 3$)$.

\subsection{Association between Low-Affinity FCGR2A/FCGR3A Haplotypes and ABA Response}

Significant association was found in the bivariate analysis between the low-affinity FCGR2A/FCGR3A haplotype variable and LDA after 12 months of treatment with ABA $(\mathrm{OR}=1.59 ; 95 \% \mathrm{CI}=1.01-2.58)$ (Table S11). Moreover, a tendency was found towards an association between the low-affinity FCGR2A/FCGR3A haplotype variable and satisfactory EULAR response at 12 months of ABA therapy $(p=0.088)$ (Table S10).

Global haplotype analysis adjusted by sex, duration of previous BTs, DAS28, and monotherapy revealed that the AC $(\mathrm{OR}=1.00)$, $\mathrm{GA}(\mathrm{OR}=1.90 ; 95 \% \mathrm{CI}=0.66-5.49)$, AA $(\mathrm{OR}=0.90 ; 95 \% \mathrm{CI}=0.28-2.91)$, and $\mathrm{GC}(\mathrm{OR}=5.24 ; 95 \% \mathrm{CI}=0.98-28.08)$ haplotypes were associated with a higher EULAR response at 6 months of ABA therapy $(p=0.013)$ (Table 4). Haplotype frequency estimation values are given in Tables S4-S9. 
Table 4. Haplotype association with EULAR response at 6 months of ABA adjusted by sex, duration of previous BTs, monotherapy, and initial DAS28.

\begin{tabular}{ccccc}
\hline FCGR2A & FCGR3A & Frequencies & $\begin{array}{c}\text { Odds Ratio } \\
\mathbf{( 9 5 \% ~ C I ) ~}\end{array}$ & $p$-Value \\
\cline { 1 - 2 } rs1801274 & rs396991 & & 1.00 & - \\
A & C & 0.2746 & $1.90(0.66-5.49)$ & 0.240 \\
G & A & 0.2662 & $0.90(0.28-2.91)$ & 0.860 \\
A & A & 0.2629 & $5.24(0.98-28.08)$ & 0.056 \\
G & C & 0.1963 &
\end{tabular}

95\% CI: confidence interval. Global haplotype association $p$-value: 0.013 .

\section{Discussion}

The interindividual response of patients diagnosed with RA and treated with BTs is very variable $[33,44,45]$. The search for biomarkers of response to these treatments is the main objective of numerous research studies carried out in recent years [9,12,46]. For this purpose, we need to evaluate the effectiveness of the treatments in different populations and find the biomarkers that determine that effectiveness. In our study, bionaïve patients showed a greater EULAR response after 6 and 12 months of ABA treatment $(53.33 \%$ and $78.57 \%$, respectively) compared to non-bionaïve patients, who had a lesser EULAR response to treatment with ABA at 6 and 12 months (31.67\% and $45.71 \%$, respectively). Furthermore, remission of the disease was greater in the bionaïve group than in the non-bionaïve group $(64.29 \%$ vs. $27.62 \%)$ after 12 months of ABA treatment. A study conducted by Cagnotto et al. in 2716 Caucasian patients (from Sweden) with RA found a greater EULAR response in bionaïve patients after 12 months of treatment with $\mathrm{ABA}\left(\mathrm{OR}_{\text {adjusted }}=4.29\right.$, $95 \% \mathrm{CI}=2.77-6.65$ ) [47]. Moreover, higher values in duration and number of previous BTs were identified as being responsible for a lower response to ABA treatment. The duration of the disease, and also age on starting treatment with $\mathrm{ABA}$ and duration of that treatment, have been identified in our study as predictors of ABA treatment response. Other studies have obtained the same results, highlighting the importance of early treatment of RA to achieve remission or, failing that, LDA [48-50]. In our patients, the administration of ABA in monotherapy, without concomitant GCs, was associated with a satisfactory EULAR response, as well as with greater remission and LDA, after 12 months of ABA treatment. However, previous studies have not found differences in effectiveness and safety between the use of ABA in monotherapy compared to ABA in combination with other DMARDs [51]. As for the clinical variables measuring the disease, the patients with lower baseline values for DAS28, NPJ, NSJ, PVAS, ESR, and HAQ had a better response to ABA treatment (greater EULAR response, LDA, and remission). These findings have been presented previously in other studies [52,53].

According to the results mentioned thus far, various biomarkers have been found as possible predictors of response to BTs in general and to ABA in particular. If we add to this the use of pharmacogenetics as a tool to achieve personalized medicine, treatments could be optimized so that the development of the disease could be delayed or arrested, avoiding the onset of irreversible disability [54]. The field of pharmacogenetics is one of those involved in this research process, as a number of SNPs have been implicated in the therapeutic response to various biological drugs $[9,21,55]$. Moreover, SNPs in the FCGR2A and FCGR3A genes have been studied as biomarkers of response to TNFis, RTX, or TCZ in various pathologies $[4,9,11,22]$. However, no study has investigated the involvement of these SNPs in the therapeutic response to ABA in patients with RA. Our results show that the FCGR2A rs1801274 polymorphism is associated with the clinical effectiveness of ABA after 6 and 12 months of treatment. The FCGR2A rs1801274-AA genotype, considered to be of high affinity, has been associated with satisfactory EULAR response after 6 months and with LDA after 6 and 12 months of ABA treatment. In line with our results, a study conducted by Jiménez Morales et al. in 55 Caucasian patients (from Spain) treated with RTX showed that individuals carrying the FCGR2A rs1801274-AA genotype had a higher rate of remission after 6 months of treatment and greater EULAR response after 6, 12, and 
18 months of treatment with $\operatorname{RTX}(p=0.035 ; \mathrm{OR}=1.53,95 \% \mathrm{CI}=1.11-21.12)$ [9]. However, in this same study, no association was found between the FCGR2A rs1801274 polymorphism and therapeutic response to TCZ in 98 Caucasian patients (from Spain) with RA [9]. Another study in 429 Caucasian patients (from Spain) diagnosed with RA and undergoing treatment with IFX showed that individuals carrying the FCGR2A rs1801274-G allele had a lower therapeutic response to this BT $(p=0.04)$ [56]. Avila-Pedretti et al. presented a study carried out in 348 Caucasian patients (from Spain) diagnosed with RA and treated with adalimumab (ADA), in which individuals carrying the FCGR2A rs1801274-GG genotype did not respond to ADA treatment after 12 weeks of treatment (GG vs. AG/AA; $p=0.022$; $\mathrm{OR}=2.54 ; 95 \% \mathrm{CI}=1.19-5.40$ ) [46]. In contrast, the results of a meta-analysis performed in 3058 Caucasian patients diagnosed with RA undergoing TNFi therapy showed that Caucasian patients carrying the FCGR2A rs1801274-AA genotype had a lower EULAR response following treatment with $\operatorname{ADA}\left(p=0.029 ; \mathrm{OR}=0.591,95 \% \mathrm{CI}=0.37-0.95 ; \mathrm{I}^{2}=0\right.$, $p_{\text {heterogeneity }}=0.770$ ) [22]. However, no significant results were obtained in patients treated with IFX and etanercept [22]. The association between the high-affinity FCGR2A-p.His131 variant and the better therapeutic response to ABA may be conditioned by an improved RA immune response [26]. Patients carrying the FCGR2A-p.His131 variant could present greater uptake and elimination of the autoimmune complexes produced by RA, decreasing tissue damage, and presenting a greater therapeutic response to ABA [26].

The FCGR3A rs396991 polymorphism has been investigated in numerous studies on RA and TNFi treatment $[4,9,11,21,22]$. No previous study has evaluated the association between the FCGR3A rs396991 polymorphism and ABA treatment in patients with RA. In our study, FCGR3A rs396991-A, a low-affinity allele, showed a tendency towards association with the EULAR response at 12 months of ABA therapy (A vs. CC; $p=0.078$ ). Similarly, in a study conducted in 87 Caucasian patients (from Spain) diagnosed with RA, a significant association was found between the FCGR3A rs396991-AA genotype and greater EULAR response after 12 months of treatment with TCZ (AA vs. C; $p=0.027$; $\mathrm{OR}=5.08 ; 95 \% \mathrm{CI}=1.20-21.33$ ) [9]. In this same study an association was found in 55 Caucasian patients (from Spain) diagnosed with RA and being treated with RTX between the FCGR3A rs396991-C allele and LDA after 18 months of treatment with RTX (C vs. AA; $p=0.077 ; \mathrm{OR}=4.90 ; 95 \% \mathrm{CI}=0.84-28.48$ ) [9]. A meta-analysis of 1427 patients receiving TNFi, RTX, and IFX therapy showed that patients being treated with RTX who carried the FCGR3A rs396991-CC and FCGR3A rs396991-CA genotypes showed a lower therapeutic response (CC/CA vs. AA; $p=0.007 ; \mathrm{OR}=0.566 ; 95 \% \mathrm{CI}=0.37-0.86 ; \mathrm{I}^{2}=45.2$, Pheterogeneity $=0.161$ ) [57]. However, no association was found between the FCGR3A rs396991 polymorphism and effectiveness of TNFis (CC/CA vs. AA; $p=0.186$ ) or IFX (CC/CA vs. AA; $p=0.065$ ) [57]. Similarly, another meta-analysis performed by Montes et al. in 429 Caucasian patients diagnosed with RA and receiving TNFi therapy found no association between the FCGR3A rs396991 polymorphism and response to BTs ( $p=0.5 ; \mathrm{OR}=1.11 ; 95 \%$ $\mathrm{CI}=0.8-1.5 ; \mathrm{I}^{2}=62$ ) [4]. The greater response to ABA in patients carrying the low affinity variant FCGR3A-p.158Phe could be due to the lower binding affinity of FCGR3A towards $\mathrm{ABA}$ so that the drug remains longer in the blood circulation, increasing the therapeutic response to $\mathrm{ABA}[4,9]$.

In our study, we analyzed the joint influence of the FCGR2A rs1801274-G (FCGR2Ap.131Arg) and FCGR3A rs396991-A (FCGR3A-p.158Phe) low-affinity alleles on the effectiveness of ABA in patients diagnosed with RA, since BTs, as we have already described, can be affected by both these SNPs. According to our results, an association was found between a larger number of low-affinity alleles and LDA after 12 months of treatment with ABA (Table S11). The presence of low-affinity FCGR2A/FCGR3A haplotypes could give rise to lower drug plasma clearance, increasing the half-life of ABA and therefore its effectiveness $[14,21]$. No study has evaluated the association between the additive power of the FCGR2A rs1801274-G and FCGR3A rs396991-A low-affinity alleles and ABA response in RA patients. A previous study in Asian patients (from Japan) diagnosed with RA and undergoing treatment with IFX showed that patients carrying low-affinity 
haplotypes had lower drug clearance compared to carriers of high-affinity haplotypes [14]. Furthermore, another study carried out by Dávila-Fajardo et al. in Caucasian patients (from Spain) treated with ADA showed an association between low-affinity haplotypes and satisfactory EULAR response $(p=0.017 ; \mathrm{OR}=1.53 ; 95 \% \mathrm{CI}=1.08-2.17)$ [21]. A study conducted in Caucasian patients (from Spain) with psoriatic arthritis treated with TNFi therapy found a significant association between low-affinity haplotypes and better therapeutic response after 6 to 8 weeks of treatment $(p=0.04)$ [58]. In our study, the presence of low-affinity FCGR2A/FCGR3A haplotypes was associated with greater clinical effectiveness of biological treatment; however, plasma ABA levels were not measured in our patients, and therefore we cannot correlate the pharmacogenetic response with the pharmacogenetics of ABA. These contradictory results regarding the influence of highand low-affinity alleles in the FCGR2A rs1801274 and FCGR3A rs396991 SNPs could be determined by the different mechanisms of action of each of the BTs indicated for treatment of RA [4]. In addition, the differential expression of FCGR2A and FCGR3A in immune system cells could also influence the contradictory response results obtained between the two receptors [15]. A previous study demonstrated that ABA showed low affinity for the FCGR2 and FCGR3 receptors, and therefore its action through complement-dependent cytotoxicity and ADCC pathways is more limited than may be the case with other BTs that do act through these immunological pathways [9,59]. Furthermore, FCGR2A and FCGR3A effect on the pathophysiology of RA could also influence the response to therapies [26].

The limitation of our study was the sample size, which could be responsible for the loss of statistically significant association between the FCGR2A rs1801274 and FCGR3A rs396991 SNPs and remission after ABA treatment. Nevertheless, all the patients were recruited from the same hospital cohort following the same therapeutic protocols by the same team of rheumatologists, which ensured the homogeneity and reliability of the clinical variables collected. All the patients diagnosed during the study period were recruited, ensuring the representativeness of the sample. Despite the limited sample size, the effects observed in these patients were clear. Further studies will be required in larger cohorts to confirm the prognostic value of the FCGR2A rs1801274 and FCGR3A rs396991 polymorphisms and the response to ABA treatment in patients diagnosed with RA.

\section{Conclusions}

In conclusion, this study shows that patients with high-affinity FCGR2A-p.131His and low-affinity FCGR3A-p.158Phe could be associated with better therapeutic response to ABA in patients diagnosed with RA. The presence of low-affinity alleles of FCGR2A and FCGR3A was associated with greater clinical effectiveness and a lower rate of LDA after treatment with ABA. In addition, lower duration of previous BTs, the use of ABA in monotherapy, non-administration of concomitant GCs, greater duration of treatment with $\mathrm{ABA}$, and early age of starting $\mathrm{ABA}$ therapy seem to be variables predictive of greater EULAR response, LDA, and remission in the individuals studied. As for clinical markers, lower baseline ESR and PVAS values are associated with better response to ABA therapy.

Supplementary Materials: The following are available online at https:/ /www.mdpi.com/article/10 .3390/jpm11060573/s1, Table S1: Hardy-Weinberg equilibrium, Table S2: Linkage disequilibrium, Table S3: Minor allele frequencies of SNPs, Table S4: Haplotype frequency estimation EULAR response at 6 months of ABA, Table S5: Haplotype frequency estimation LDA at 6 months of ABA, Table S6: Haplotype frequency estimation remission at 6 months of ABA, Table S7: Haplotype frequency estimation EULAR response at 12 months of ABA, Table S8: Haplotype frequency estimation LDA at 12 months of ABA, Table S9: Haplotype frequency estimation remission at 12 months of ABA, Table S10: Predictors of EULAR response at 6 and 12 months of treatment with abatacept in rheumatoid arthritis patients (bivariate analysis), Table S11: Predictors of LDA at 6 and 12 months of treatment with abatacept in rheumatoid arthritis patients (bivariate analysis), Table S12: Predictors of remission at 6 and 12 months of treatment with abatacept in rheumatoid arthritis patients (bivariate analysis). 
Author Contributions: N.M.P. and M.d.M.M.M. conceived and designed the experiments; N.M.P. performed the experiments; N.M.P. and M.d.M.M.M. were involved in sample collection; N.M.P. and C.P.R. analyzed the data; F.M.M. and J.E.M.d.1.P. contributed materials and analysis tools; N.M.P. was responsible for writing-original draft preparation; N.M.P., M.d.M.M.M., C.P.R., F.M.M., and A.D. reviewed and edited the manuscript; N.M.P., M.d.M.M.M., and C.P.R. reviewed the analysis and the interpretation; A.J.M. was responsible for supervision and funding acquisition. All authors participated in critically reviewing the manuscript for intellectual content. All authors have read and agreed to the published version of the manuscript.

Funding: This work was partly supported by a contract for Noelia Márquez Pete from the University of Granada and the Fundación de Investigación Biosanitaria de Andalucía Oriental (FIBAO). The Virgen de las Nieves University Hospital Biobank was supported by grants co-funded by ERDF funds (EU) from the Instituto de Salud Carlos III (PT13/0010/0039).

Institutional Review Board Statement: The study was conducted according to the guidelines of the Declaration of Helsinki, and approved by the Ethics Committee of University Hospital Virgen de las Nieves (HUVN) (20 June 2014).

Informed Consent Statement: Informed consent was obtained from all subjects involved in the study.

Acknowledgments: The authors would like to acknowledge all the patients who participated in the study, as well as the professionals from the University Hospital Virgen de las Nieves that contributed to the management of the samples, especially the nursing team from the Rheumatology Department and the professionals of outpatient pharmacy service. The results of this research study are part of the doctoral thesis to be submitted by Noelia Márquez Pete at the University of Granada, carried out within the "Clinical Medicine and Public Health" doctoral program.

Conflicts of Interest: The authors declare that there is no conflict of interest that could be perceived as prejudicing the impartiality of the research reported, and that there are no competing financial interests in relation to the work described in this article.

\begin{tabular}{ll} 
Abbreviations \\
ABA & abatacept \\
ACPA & anti-cyclic citrullinated peptide antibodies \\
ACR & American College of Rheumatology \\
ADCC & antibody-dependent cellular cytotoxicity \\
Arg & arginine \\
bDMARDs & biologic disease-modifying antirheumatic drugs \\
BT & biological therapy \\
CRP & C-reactive protein \\
csDMARDs & conventional synthetic disease-modifying antirheumatic drugs \\
CTLA-4 & cytotoxic T-lymphocyte-associated antigen 4 \\
DAS28 & 28-joints Disease Activity Score \\
DMARDs & disease-modifying antirheumatic drugs \\
ESR & erythrocyte sedimentation rate \\
EULAR & European League Against Rheumatism \\
FC & fragment crystallizable \\
FCGR & Fc-gamma receptor \\
GC & glucocorticoid \\
HAQ & Health Assessment Questionnaire score \\
His & histidine \\
HWE & Hardy-Weinberg equilibrium \\
IFX & infliximab \\
IgG1 & human immunoglobulin G1 \\
IV & intravenous \\
LDA & low-activity disease \\
LFN & leflunomide \\
MTX & methotrexate \\
\hline
\end{tabular}




$\begin{array}{ll}\text { NIJ } & \text { number of inflamed joints } \\ \text { NK } & \text { natural killer } \\ \text { NPJ } & \text { number of painful joints } \\ \text { OR } & \text { odds ratio } \\ \text { PCR } & \text { polymerase chain reaction } \\ \text { Phe } & \text { phenylalanine } \\ \text { PVAS } & \text { patient's visual analogue scale } \\ \text { RA } & \text { rheumatoid arthritis } \\ \text { RF } & \text { rheumatoid factor } \\ \text { RTX } & \text { rituximab } \\ \text { SC } & \text { subcutaneous } \\ \text { SNP } & \text { single-nucleotide polymorphism } \\ \text { TCZ } & \text { tocilizumab } \\ \text { TNFi } & \text { tumor necrosis factor inhibitor } \\ \text { tsDMARDs } & \text { targeted synthetic disease-modifying antirheumatic drugs } \\ \text { Val } & \text { valine }\end{array}$

\section{References}

1. Blair, H.A.; Deeks, E.D. Abatacept: A Review in Rheumatoid Arthritis. Drugs 2017, 77, 1221-1233. [CrossRef]

2. Gazeau, P.; Alegria, G.C.; Devauchelle-Pensec, V.; Jamin, C.; Lemerle, J.; Bendaoud, B.; Brooks, W.H.; Saraux, A.; Cornec, D.; Renaudineau, Y. Memory B Cells and Response to Abatacept in Rheumatoid Arthritis. Clin. Rev. Allergy Immunol. 2017, 53, 166-176. [CrossRef]

3. Lobo, E.D.; Hansen, R.J.; Balthasar, J.P. Antibody Pharmacokinetics and Pharmacodynamics. J. Pharm. Sci. 2004, 93, 2645-2668. [CrossRef]

4. Montes, A.; Perez-Pampin, E.; Joven, B.; Carreira, P.; Fernandez-Nebro, A.; Ordóñez, M.D.C.; Navarro-Sarabia, F.; Moreira, V.; Vasilopoulos, Y.; Sarafidou, T.; et al. FCGR polymorphisms in the treatment of rheumatoid arthritis with Fc-containing TNF inhibitors. Pharmacogenomics 2015, 16, 333-345. [CrossRef] [PubMed]

5. Tracey, D.; Klareskog, L.; Sasso, E.H.; Salfeld, J.G.; Tak, P.P. Tumor necrosis factor antagonist mechanisms of action: A comprehensive review. Pharmacol. Ther. 2008, 117, 244-279. [CrossRef] [PubMed]

6. Nimmerjahn, F.; Ravetch, J.V. Fc $\gamma$ Receptors: Old Friends and New Family Members. Immunology 2006, 24, 19-28. [CrossRef] [PubMed]

7. Zhu, X.; Meng, G.; Dickinson, B.L.; Li, X.; Mizoguchi, E.; Miao, L.; Wang, Y.; Robert, C.; Wu, B.; Smith, P.D.; et al. MHC Class I-Related Neonatal Fc Receptor for IgG Is Functionally Expressed in Monocytes, Intestinal Macrophages, and Dendritic Cells. J. Immunol. 2001, 166, 3266-3276. [CrossRef]

8. Beenhouwer, D.; Wallis, R.; Broder, M.E.; Furst, D. Mechanisms of action of tumor necrosis factor antagonist and granulomatous infections. J. Rheumatol. 2004, 31, 1888-1892.

9. Morales, A.J.; Maldonado-Montoro, M.; de la Plata, J.E.M.; Ramírez, C.P.; Daddaoua, A.; Alarcón-Payer, C.; Msc, M.E.R.; Collado, C.G. FCGR2A/FCGR3A Gene Polymorphisms and Clinical Variables as Predictors of Response to Tocilizumab and Rituximab in Patients with Rheumatoid Arthritis. J. Clin. Pharmacol. 2019, 59, 517-531. [CrossRef]

10. Quartuccio, L.; Fabris, M.; Pontarini, E.; Salvin, S.; Zabotti, A.; Benucci, M.; Manfredi, M.; Biasi, D.; Ravagnani, V.; Atzeni, F.; et al. The 158VV Fcgamma receptor 3A genotype is associated with response to rituximab in rheumatoid arthritis: Results of an Italian multicentre study. Ann. Rheum. Dis. 2013, 73, 716-721. [CrossRef]

11. Pál, I.; Szamosi, S.; Hodosi, K.; Szekanecz, Z.; Váróczy, L. Effect of Fc $\gamma$-receptor 3a (FCGR3A) gene polymorphisms on rituximab therapy in Hungarian patients with rheumatoid arthritis. RMD Open 2017, 3, e000485. [CrossRef]

12. Liu, D.; Tian, Y.; Sun, D.; Sun, H.; Jin, Y.; Dong, M. The FCGR3A polymorphism predicts the response to rituximab-based therapy in patients with non-Hodgkin lymphoma: A meta-analysis. Ann. Hematol. 2016, 95, 1483-1490. [CrossRef] [PubMed]

13. Nimmerjahn, F.; Ravetch, J.V. Fc $\gamma$ receptors as regulators of immune responses. Nat. Rev. Immunol. 2008, 8, 34-47. [CrossRef] [PubMed]

14. Nishio, S.; Yamamoto, T.; Kaneko, K.; Tanaka-Matsumoto, N.; Muraoka, S.; Kaburaki, M.; Kusunoki, Y.; Takagi, K.; Kawai, $\mathrm{S}$. Pharmacokinetic study and $\mathrm{Fc} \gamma$ receptor gene analysis in two patients with rheumatoid arthritis controlled by low-dose infliximab. Mod. Rheumatol. 2009, 19, 329-333. [CrossRef] [PubMed]

15. Antonatos, C.; Stavrou, E.F.; Evangelou, E.; Vasilopoulos, Y. Exploring pharmacogenetic variants for predicting response to anti-TNF therapy in autoimmune diseases: A meta-analysis. Pharmacogenomics 2021, 22, 435-445. [CrossRef]

16. Van Der Pol, W.-L.; Van De Winkel, J.G.J. IgG receptor polymorphisms: Risk factors for disease. Immunogenetics 1998, 48, $222-232$. [CrossRef] [PubMed]

17. Chai, L.; Song, Y.-Q.; Leung, W.K. Genetic polymorphism studies in periodontitis and Fc $\gamma$ receptors. J. Periodontal Res. 2011, 47, 273-285. [CrossRef] 
18. Cañete, J.D.; Suarez, B.; Hernandez, M.V.; Sanmarti, R.; Rego, I.; Celis, R.; Moll, C.; Pinto, J.A.; Blanco, F.J.; Lozano, F. Influence of variants of $\mathrm{F} c \gamma$ receptors IIA and IIIA on the American College of Rheumatology and European League Against Rheumatism responses to anti-tumour necrosis factor $\alpha$ therapy in rheumatoid arthritis. Ann. Rheum. Dis. 2009, 68, 1547-1552. [CrossRef] [PubMed]

19. Binstadt, B.A.; Geha, R.S.; Bonilla, F.A. IgG Fc receptor polymorphisms in human disease: Implications for intravenous immunoglobulin therapy. J. Allergy Clin. Immunol. 2003, 111, 697-703. [CrossRef] [PubMed]

20. Hatjiharissi, E.; Xu, L.; Santos, D.D.; Hunter, Z.R.; Ciccarelli, B.T.; Verselis, S.; Modica, M.; Cao, Y.; Manning, R.J.; Leleu, $\mathrm{X}$.; et al. Increased natural killer cell expression of CD16, augmented binding and ADCC activity to rituximab among individuals expressing the Fc $\gamma$ RIIIa-158 V/V and V/F polymorphism. Blood 2007, 110, 2561-2564. [CrossRef]

21. Dávila-Fajardo, C.L.; Van Der Straaten, T.; Baak-Pablo, R.; Caballero, C.M.; Barrera, J.C.; Huizinga, T.W.; Guchelaar, H.-J.; Swen, J.J. FcGR genetic polymorphisms and the response to adalimumab in patients with rheumatoid arthritis. Pharmacogenomics 2015, 16, 373-381. [CrossRef]

22. Lee, Y.H.; Bae, S.-C. Associations between PTPRC rs10919563 A/G and FCGR2A R131H polymorphisms and responsiveness to TNF blockers in rheumatoid arthritis: A meta-analysis. Rheumatol. Int. 2016, 36, 837-844. [CrossRef]

23. Tutuncu, Z.; Kavanaugh, A.; Zvaifler, N.; Corr, M.; Deutsch, R.; Boyle, D. Fcgamma receptor type IIIA polymorphisms influence treatment outcomes in patients with inflammatory arthritis treated with tumor necrosis factor alpha-blocking agents. Arthritis Rheum. 2005, 52, 2693-2696. [CrossRef]

24. Morales-Lara, M.J.; Conesa-Zamora, P.; García-Simón, M.S.; Pedrero, F.; Santaclara, V.; Perez-Guillermo, M.; Soriano-Navarro, E. Association between the FCGR3A V158F polymorphism and the clinical response to infliximab in rheumatoid arthritis and spondyloarthritis patients. Scand. J. Rheumatol. 2010, 39, 518-520. [CrossRef]

25. Kastbom, A.; Bratt, J.; Ernestam, S.; Lampa, J.; Padyukov, L.; Söderkvist, P.; Skogh, T. Fcgamma receptor type IIIA genotype and response to tumor necrosis factor alpha-blocking agents in patients with rheumatoid arthritis. Arthritis Rheum. 2007, 56, 448-452. [CrossRef] [PubMed]

26. Okada, Y.; Wu, D.; Trynka, G.; Raj, T.; Terao, C.; Ikari, K.; Kochi, Y.; Ohmura, K.; Suzuki, A.; Yoshida, S.; et al. Genetics of rheumatoid arthritis contributes to biology and drug discovery. Nature 2014, 506, 376-381. [CrossRef] [PubMed]

27. Frisell, T.; Askling, J. Comment on: Comparative effectiveness of abatacept, rituximab, tocilizumab and TNFi biologics in RA: Results from the nationwide Swedish register: Reply. Rheumatology 2019, 58, 1507-1509. [CrossRef]

28. Pete, N.M.; Montoro, M.D.M.M.; Ramírez, C.P.; Martín, A.S.; De La Plata, J.E.M.; Martínez, F.M.; Caliz, R.C.; Daddaoua, A.; Tortosa, M.D.C.R.; Morales, A.J. Impact of Single-Nucleotide Polymorphisms of CTLA-4, CD80 and CD86 on the Effectiveness of Abatacept in Patients with Rheumatoid Arthritis. J. Pers. Med. 2020, 10, 220. [CrossRef] [PubMed]

29. Singh, J.A.; Saag, K.G.; Bridges, S.L., Jr.; Akl, E.A.; Bannuru, R.R.; Sullivan, M.C.; Vaysbrot, E.; McNaughton, C.; Osani, M.; Shmerling, R.H.; et al. 2015 American College of Rheumatology Guideline for the Treatment of Rheumatoid Arthritis. Arthritis Rheumatol. 2016, 68, 1-26. [CrossRef] [PubMed]

30. Felson, D.T.; Anderson, J.J. Methodological and statistical approaches to criteria development in rheumatic diseases. Bailliere's Clin. Rheumatol. 1995, 9, 253-266. [CrossRef]

31. Wells, G.; Becker, J.-C.; Teng, J.; Dougados, M.; Schiff, M.; Smolen, J.; Aletaha, D.; Van Riel, P.L.C.M. Validation of the 28-joint Disease Activity Score (DAS28) and European League Against Rheumatism response criteria based on C-reactive protein against disease progression in patients with rheumatoid arthritis, and comparison with the DAS28 based on erythrocyte sedimentation rate. Ann. Rheumathol. Dis. 2008, 68, 954-960. [CrossRef]

32. Prevoo, M.L.L.; Hof, M.A.V.; Kuper, H.H.; Van Leeuwen, M.A.; Van De Putte, L.B.A.; Van Riel, P.L.C.M. Modified disease activity scores that include twenty-eight-joint counts development and validation in a prospective longitudinal study of patients with rheumatoid arthritis. Arthritis Rheumathol. 1995, 38, 44-48. [CrossRef]

33. Smolen, J.S.; Landewé, R.B.M.; Bijlsma, J.W.J.; Burmester, G.R.; Dougados, M.; Kerschbaumer, A.; McInnes, I.B.; Sepriano, A.; van Vollenhoven, R.F.; de Wit, M.; et al. EULAR recommendations for the management of rheumatoid arthritis with synthetic and biological disease-modifying antirheumatic drugs: 2019 update. Ann. Rheumathol. Dis. 2020, 79, 685-699. [CrossRef]

34. Van Gestel, A.M.; Anderson, J.J.; Van Riel, P.L.; Boers, M.; Haagsma, C.J.; Rich, B.; Wells, G.; Lange, M.L.; Felson, D. ACR and EULAR improvement criteria have comparable validity in rheumatoid arthritis trials. American College of Rheumatology European League of Associations for Rheumatology. J. Rheumatol. 1999, 26, 705-711. [PubMed]

35. Felson, D.T.; Smolen, J.S.; Wells, G.; Zhang, B.; Van Tuyl, L.H.D.; Funovits, J.; Aletaha, D.; Allaart, C.F.; Bathon, J.; Bombardieri, S.; et al. American College of Rheumatology/European League Against Rheumatism provisional definition of remission in rheumatoid arthritis for clinical trials. Arthritis Rheumathol. 2011, 63, 573-586. [CrossRef] [PubMed]

36. Team RC. R: A Language and Environment for Statistical Computing; R Core Team: Vienna, Austria, 2013.

37. Purcell, S.; Neale, B.; Todd-Brown, K.; Thomas, L.; Ferreira, M.A.R.; Bender, D.; Maller, J.; Sklar, P.; de Bakker, P.I.W.; Daly, M.J.; et al. PLINK: A Tool Set for Whole-Genome Association and Population-Based Linkage Analyses. Am. J. Hum. Genet. 2007, 81, 559-575. [CrossRef]

38. Zhai, C.; Li, S.; Feng, W.; Shi, W.; Wang, J.; Wang, Q.; Chai, L.; Zhang, Q.; Yan, X.; Li, M. Association of interleukin-17a rs2275913 gene polymorphism and asthma risk: A meta-analysis. Arch. Med. Sci. 2018, 14, 1204-1211. [CrossRef]

39. Sole, X.; Guinó, E.; Valls, J.; Iniesta, R.; Moreno, V. SNPStats: A web tool for the analysis of association studies. Bioinformatics 2006, 22, 1928-1929. [CrossRef] 
40. Barrett, J.C.; Fry, B.; Maller, J.; Daly, M.J. Haploview: Analysis and visualization of LD and haplotype maps. Bioinformatics 2005, 21, 263-265. [CrossRef] [PubMed]

41. Alyousef, Y.M.; Borgio, J.F.; AbdulAzeez, S.; Al-Masoud, N.; Al-Ali, A.A.; Al-Shwaimi, E.; Al-Ali, A.K. Association of MBL2 Gene Polymorphism with Dental Caries in Saudi Children. Caries Res. 2016, 51, 12-16. [CrossRef]

42. AbdulAzeez, S.; Al-Nafie, A.N.; Al-Shehri, A.; Borgio, J.F.; Baranova, E.V.; Al-Madan, M.S.; Al-Ali, R.A.; Al-Muhanna, F.; Al-Ali, A.; Al-Mansori, M.; et al. Intronic Polymorphisms in the CDKN2B-AS1 Gene Are Strongly Associated with the Risk of Myocardial Infarction and Coronary Artery Disease in the Saudi Population. Int. J. Mol. Sci. 2016, 17, 395. [CrossRef]

43. Al Asoom, L.I.; Alsuwat, H.S.; Rafique, N.; Al Makhaita, M.; AlAmoudi, W.; AbdulAzeez, S.; Borgio, J.F. Functional DNA variations associated with Saudi female with low VO2max: A pilot microarray study. Am. J. Transl. Res. 2019, 11, 3659-3670.

44. Nam, J.; Winthrop, K.; Van Vollenhoven, R.; Pavelka, K.; Valesini, G.; Hensor, E.; Worthy, G.; Landewe, R.; Smolen, J.; Emery, P.; et al. Current evidence for the management of rheumatoid arthritis with biological disease-modifying antirheumatic drugs: A systematic literature review informing the EULAR recommendations for the management of RA. Ann. Rheumathol. Dis. 2010, 69, 976-986. [CrossRef] [PubMed]

45. Lee, Y.H.; Bae, S.C. Comparative efficacy and safety of tocilizumab, rituximab, abatacept and tofacitinib in patients with active rheumatoid arthritis that inadequately responds to tumor necrosis factor inhibitors: A Bayesian network meta-analysis of randomized controlled trials. Int. J. Rheum. Dis. 2016, 19, 1103-1111. [PubMed]

46. Avila-Pedretti, G.; Tornero, J.; Fernández-Nebro, A.; Blanco, F.; Gonzalez-Alvaro, I.; Cañete, J.D.; Maymó, J.; Alperiz, M.; Fernandez-Gutierrez, B.; Olivè, A.; et al. Variation at FCGR2A and Functionally Related Genes Is Associated with the Response to Anti-TNF Therapy in Rheumatoid Arthritis. PLoS ONE 2015, 10, e0122088. [CrossRef]

47. Cagnotto, G.; Willim, M.; Nilsson, J.; Compagno, M.; Jacobsson, L.T.H.; Saevarsdottir, S.; Turesson, C. Abatacept in rheumatoid arthritis: Survival on drug, clinical outcomes, and their predictors-data from a large national quality register. Arthritis Res. 2020, 22, 1-11. [CrossRef] [PubMed]

48. Harrold, L.R.; Litman, H.J.; Connolly, S.E.; Kelly, S.; Hua, W.; Alemao, E.; Rosenblatt, L.; Rebello, S.; Kremer, J.M. A window of opportunity for abatacept in RA: Is disease duration an independent predictor of low disease activity/remission in clinical practice? Clin. Rheumatol. 2017, 36, 1215-1220. [CrossRef] [PubMed]

49. Anderson, J.J.; Wells, G.; Verhoeven, A.C.; Felson, D.T. Factors predicting response to treatment in rheumatoid arthritis: The importance of disease duration. Arthritis Rheumathol. 2000, 43, 22-29. [CrossRef]

50. Möttönen, T.; Hannonen, P.; Korpela, M.; Nissilä, M.; Kautiainen, H.; Ilonen, J.; Laasonen, L.; Kaipiainen-Seppänen, O.; Franzen, P.; Helve, T.; et al. Delay to institution of therapy and induction of remission using single-drug or combination-disease-modifying antirheumatic drug therapy in early rheumatoid arthritis. Arthritis Rheumathol. 2002, 46, 894-898. [CrossRef]

51. Paul, D.; Fazeli, M.S.; Mintzer, L.; Duarte, L.; Gupta, K.; Ferri, L. Comparative efficacy and safety of current therapies for early rheumatoid arthritis: A systematic literature review and network meta-analysis. Clin. Exp. Rheumatol. 2020, 38, 1008-1015.

52. Lee, J.S.; Ahmad, H.; Shim, S.-C.; Bae, S.-C.; Song, Y.W.; Lee, E.Y. High Proportion of Subjective Component to the Disease Activity Score is Associated with Favorable Response to Abatacept in Rheumatoid Arthritis. Patient Cent. Outcomes Res. 2018, 12, 319-326. [CrossRef]

53. Jurgens, M.S.; Overman, C.L.; Jacobs, J.W.G.; Geenen, R.; Cuppen, B.V.J.; Marijnissen, A.C.A.; Bijlsma, J.W.J.; Welsing, P.M.J.; Lafeber, F.P.J.G.; Van Laar, J.M.; et al. Contribution of the Subjective Components of the Disease Activity Score to the Response to Biologic Treatment in Rheumatoid Arthritis. Arthritis Rheumathol. 2015, 67, 923-928. [CrossRef]

54. Alten, R.; Mariette, X.; Lorenz, H.-M.; Galeazzi, M.; Cantagrel, A.; Nüßlein, H.G.; Chartier, M.; Elbez, Y.; Rauch, C.; Le Bars, M. Real-world predictors of 12-month intravenous abatacept retention in patients with rheumatoid arthritis in the ACTION observational study. RMD Open 2017, 3, e000538. [CrossRef] [PubMed]

55. Maldonado-Montoro, M.; Cañadas-Garre, M.; González-Utrilla, A.; Plaza-Plaza, J.C.; Calleja-Hernández, M. Ÿngel Genetic and clinical biomarkers of tocilizumab response in patients with rheumatoid arthritis. Pharmacol. Res. 2016, 111, 264-271. [CrossRef] [PubMed]

56. Montes, A.; Perez-Pampin, E.; Narvaez, J.; Cañete, J.D.; Navarro-Sarabia, F.; Moreira, V.; Fernández-Nebro, A.; Ordóñez, M.D.C.; de la Serna, A.R.; Magallares, B.; et al. Association of FCGR2A with the response to infliximab treatment of patients with rheumatoid arthritis. Pharm. Genom. 2014, 24, 238-245. [CrossRef] [PubMed]

57. Lee, Y.H.; Bae, S.-C.; Song, G.G. Functional FCGR3A 158 V/F and IL-6 -174 C/G polymorphisms predict response to biologic therapy in patients with rheumatoid arthritis: A meta-analysis. Rheumatol. Int. 2014, 34, 1409-1415. [CrossRef] [PubMed]

58. Julià, M.; Guilabert, A.; Lozano, F.; Suarez-Casasús, B.; Moreno, N.; Carrascosa, J.M.; Ferrándiz, C.; Pedrosa, E.; Alsina-Gibert, M.; Mascaró, J.M. The Role of Fc $\gamma$ Receptor Polymorphisms in the Response to Anti-Tumor Necrosis Factor Therapy in Psoriasis. JAMA Dermatol. 2013, 149, 1033-1039. [CrossRef] [PubMed]

59. Davis, P.M.; Abraham, R.; Xu, L.; Nadler, S.G.; Suchard, S.J. Abatacept binds to the Fc receptor CD64 but does not mediate complement-dependent cytotoxicity or antibody-dependent cellular cytotoxicity. J. Rheumatol. 2007, 34, $2204-2210$. 